\title{
Efficacy of Mitomycin $c$ in Reducing the Recurrence of Urethral Stricture after Visual Internal Urethrotomy (VIU)
}

\author{
A.H.Al-Falah, A.S.Ahmed,A.F.Abd El Azeem and S.A.Salama \\ Urology Dept., Faculty of Medicine, Benha Univ., Benha, Egypt \\ E-Mail:Baher56@gmail.com
}

\begin{abstract}
Urethral stricture remains one of the oldest known urologic diseases and also still a common problem with high morbidity. Recurrence rate of VIU is high in different studies ranging from $20 \%$ to $60 \%$, the aim of this study was to assess the efficacy of MMC in reducing the recurrence of urethral stricture after VIU. Our consider incorporated 30 patients torment from $<2 \mathrm{~cm}$ urethral stricture, starting with might 2018 should november 2019. These patients were randomized under two aggregations; gathering An (study group) incorporated 15 patients who were subjected with intralesional MMC then afterward VIU, What's more one assembly b (control group) incorporated 15 patients who were subjected to VIU best. Utilizing An Cold-knife those urethrotomy might have been performed under immediate dream What's more incisions were aggravated during 12-, 5-, What's more 7 O'clock positions taken after Toward intralesional infusion from claiming MMC. Every one patients were took after dependent upon to 6 months and the stricture repeat rate might have been compared the middle of those two aggregation. Of the aggregate 30 patients, 4 patients clinched alongside gathering a and 3 tolerant On one assembly b were lost should catch up in the initial 2 months Furthermore Subsequently were dropped from the ponder. Those test might have been consequently decreased will 23 patients who were separated under two aggregations. Bunch An (study group) comprised 11 patients who were subjected should intralesional mitomycin c's after VIU. Aggregation b (control group) comprised 12 patients who underwent VIU main. There might have been statistically critical Contrast the middle of 2 bunches in regards will stricture repeat ; 2 patients On one assembly a (18. 2\%) Furthermore 7 patients On bunch b (58. 3\%) required repeat ( $\mathrm{p}=0.02)$. Various intralesional MMC injections Emulating VIU need An possibility with markedly decrease those repeat about urethral stricture.
\end{abstract}

\section{Introduction}

Urethral stricture remains a standout amongst those most seasoned referred to urologic illnesses Also Additionally even now a as a relatable point issue for helter skelter horribleness. Damage of the epithelium from claiming urethra alternately those underlying corpus spongiosum might bring about scar shaping prompting urethral stricture which influences negatively caliber of voiding [1]. Despite it camwood happen clinched alongside At whatever and only the urethra, over A large portion from claiming cases would introduce in the bulbar urethra. Those A large portion regular reason for urethral stricture would iatrogenic reasons (catheterization and transurethral surgery), incendiary makes Furthermore trauma (pelvic fracture) [2]. Those way occasions in the pathogenesis from claiming urethral stricture would over the top collagen amalgamation Furthermore progressions On piece of the extracellular grid. Urethral stricture need been mostaccioli figured out how with urethral dilatation and VIU [3].

Repeat rate for VIU may be secondary in distinctive investigations extending from $20 \%$ will $60 \%$,many systems bring been embraced to decrease those repeat for stricture following VIU a few past investigations required assessed those impact for antifibrotic medications once urethral strictures, for example, mitomycin c's , halofuginone, and glucocorticoids [4].

Mitomycin c (MMC) will be Additionally a intense chemotherapeutic agenize Furthermore also need antimicrobial action by hindering dna amalgamation. It inhibits fibroblast proliferation, mitosis, protein What's more collagen amalgamation Furthermore angiogenesis [5].

Consequently the theory for our contemplate might have been that intralesional infusion of MMC after VIU possibility to stamped lessen the repeat for stricture urethra.

\section{Materials and methods}

This might have been a randomized controlled trial led in the Branch from claiming urology during Benha college Hospitals, from might 2019 until november 2019. What added up to 30 recently diagnosed instances about urethral stricture were included in the study. Those patients might have been just as partitioned under two groups, one assembly a (study) comprised 15 patients who were subjected to intralesional mitomycin $\mathrm{c}$ following VIU. Aggregation b (controls) comprised 15 patients who underwent VIU best. We included at patients for recently diagnosed foremost urethral stricture who finished the span of the consider What's more required urethral strictures of a most extreme length about $2 \mathrm{~cm}$, regardless of etiology, as stated by those discoveries of a retrograde urethrogram supplemented Eventually Tom's perusing uroflowmetry.

Patients with a maximal stream rate (MFR) for less 10 $\mathrm{mL} / \mathrm{s}$ Furthermore for foremost urethral stricture were incorporated in the contemplate. We excluded patients for Visually impaired urethral strictures, numerous urethral strictures, unpredictable stricture, repetitive stricture following neglected VIU. Finish history, examination, Also important investigations were finished altogether patients. To aggregation $\mathrm{A}$, mitomycin $\mathrm{c}$ might have been injected after VIU during those webpage in the 12,5 , What's more 7 o'clock positions for a standard needle utilizing inflexible cystoscope, clinched alongside gathering B, VIU best might have been performed. Patients done both Assemblies were consistently took after up for 6 months toward 1 month,3 months Furthermore 6 months. Those catch up comprised for history, examination, Also uroflowmetry Also retrograde urethrogram done patients with manifestations alternately indications sugi repetitive urethral stricture. Indications of repeat incorporated powerless pee stream, feeling from claiming inadequate bladder emptying, alternately repetitive urinary tract infections. Indications from claiming repeat were An 
noteworthy expand clinched alongside postvoid lingering pee for pelvi-abdominal ultrasound, diminished Qmax $(<10$ $\mathrm{mL} / \mathrm{second}$ ), or stricture Likewise confirmed by retrograde urethrogram. Nonattendance for side effects alternately indications for repetitive stricture in any tolerant finally catch up characterized the accomplishment of the technique. Qualities $\mathrm{p}<0.05$ were acknowledged critical in the dissection. The information were gathered on An organized proforma sheet Also were broke down Eventually Tom's perusing utilization of SPSS ver. 20.

\section{Results}

Of the total 30 patients, 4 patients in group $\mathrm{A}$ and 3 patients in group B were lost to follow-up in the first 2 months and hence were dropped from the study. The sample was thus reduced to 23 patients who were divided into two groups. Group A (study) comprised 11 patients who were subjected to intralesional mitomycin $\mathrm{C}$ after
VIU. Group B (controls) comprised 12 patients who underwent VIU only. The mean age of the patients in group A was 27.31 \pm 10.1 years and that in group B was $30.1 \pm 11.4$ years $(p=0.037)$. Regarding the etiology of urethral stricture, traumatic urethral injury were the most common causes in both groups. The mean preoperative Qmax in patients of group A was $8.5 \pm 5.1 \mathrm{~mL} / \mathrm{s}$, whereas it was $9.2 \pm 4.7 \mathrm{~mL} / \mathrm{s}$ in patients of group $\mathrm{B}$. The mean stricture length in group A was $1.86 \pm 0.2 \mathrm{~cm}$, whereas it was $1.67 \pm 0.4 \mathrm{~cm}$ in group B. No significant differences were observed in maximum flow or mean stricture length. We included patients with strictures of only the anterior urethra. Patients in both groups were regularly followed up for 6 months for evaluation of any recurrence. Regarding the association of recurrence, 2 patients in group A $(18.2 \%)$ and 7 patients in group B $(58.3 \%)$ had recurrence $(\mathrm{p}=0.02)$ Table $(1)$.

Table (1) Comparing the two groups regarding recurrence.

\begin{tabular}{lcccc}
\hline Recurrence & $\begin{array}{c}\text { Group A (n=11) } \\
\text { No. (\%) }\end{array}$ & $\begin{array}{c}\text { Group B (n=12) } \\
\text { No. (\%) }\end{array}$ & $\square \square$ & p-value \\
\hline Overall recurrence & $2(18.2)$ & $7(58.3)$ & 5.429 & $0.02^{*}$ \\
Timing of recurrence & $0(0)$ & $4(33.3)$ & & \\
Recurrence at 1month & $1(9.1)$ & $1(8.3)$ & 7.839 & $0.02^{*}$ \\
Recurrence at 3months & $1(9.1)$ & $2(16.6)$ & & \\
Recurrence at 6months & & & \\
\hline
\end{tabular}

\section{Discussion}

Those inside urethrotomy technique includes incising strictured Furthermore solid tissues will permit those scar to extend Also permits those lumen will mend extended [6]. Internal urethrotomy doesn't attain a epithelial close estimation However rather means on separate those scarred epithelium with the goal that the recuperating happens Toward optional plan. The pathophysiology of the recuperating transform Emulating internal urethrotomy remains poorly understood, it may be possibility that Assuming that epithelialisation progresses in front of wound contraction, the inner urethrotomy might be An victory Anyway Assuming that wound withdrawal altogether narrows those lumen preceding fruition of epithelialisation, the stricture recurs [6]. At whatever drug alternately system that might delay wound withdrawal brings about diminishing those stricture repeat. Mitomycin $\mathrm{c}$ is a antineoplastic alkylating anti-microbial determined starting with streptomyces caespitosus, it demonstrations Eventually Tom's perusing cross-linking dna between guanine, adenine prompting hindering dna amalgamation. It likewise suppresses cell division rna Also protein union. Therefore, it will be advantageous in delaying those methodology from claiming wound recuperating Toward keeping answer from claiming fibroblasts and epithelial phones Furthermore hindering collagen union [7]. It may be recommended that it could delay wound withdrawal. Different investigations looking into mitomycin $\mathrm{c}$ have turned out its viability to keeping fibroblast burgeoning Also improvement of fibrosis then afterward myringotomy What's more trabeculectomy, Along these lines moving forward those victory rate for these methods [8]. With our knowledge, this may be prospective, randomized, clinical trial with assess those viability of mitomycin c's provision On inside urethrotomy.

Mazdak et al. , assessed VIU for MMC to bulbar urethral strictures by randomizing patients should VIU with $(n=20)$ alternately without $(n=20)$ MMC. After 6 months from claiming follow-up, there were essentially fewer stricture recurrences in the VIU with MMC companion $(10 \%$ vs. $50 \%, \mathrm{p}=0.006)$. Further contemplate Toward ali et al. , likewise utilized An randomized, regulated plan However with An bigger accomplice about patients for both bulbar Furthermore penile urethral strictures who didn't have repetitive strictures, former VIU alternately former urethroplasty (VIU with MMC, $n=78$; VIU without MMC, $n=73$ ). It might have been found that fundamentally fewer patients in the VIU for MMC companion encountered stricture repeat over a 18 month catch up period (14. $1 \%$ vs. 36. 9\%, p=0. 002). MMC might have been injected after VIU In An focus from claiming $0.1 \%$ during those 1-, 11-, and 12-o'clock positions, however, those aggregate measurement of MMC might have been not portrayed.

Our study is An prospective study led for (30) patients suffice starting with urethral strictures went to the urology section about Benha school healing centers between might 2018 Furthermore november 2019, the patients randomized under two groups: aggregation An (study group) incorporated 15 patients who were subjected will intralesional mitomycin c following VIU and one assembly 
b (control group) incorporated 15 patients who were subjected with VIU just.

Of the downright 30 patients, 4 patients Previously, gathering a and 3 tolerant for assembly $b$ were lost will catch up in the main 2 months Also henceforth were dropped from those examine. Those test might have been accordingly diminished will 23 patients who were isolated under two Assemblies. One assembly An (study group) comprised 11 patients who were subjected should intralesional mitomycin $\mathrm{c}$ then afterward VIU. One assembly $b$ (control group) comprised 12 patients who underwent VIU main.

In regards to should stricture repeat Previously, our study, there might have been huge decline in gathering $\mathrm{A}$; 2 patients (18. 2\%) Furthermore with gathering $\mathrm{B} ; 7$ patients (58. 3\%), $(\mathrm{p}=0.02)$. Our investigation need meanings for know urologists who need aid included in the management from claiming urethral stricture. This novel procedure of utilizing intralesional mitomycin $\mathrm{c}$ need opened new windows of exploration to individual urologists Previously, urethral stricture malady. Further Look into will be required on the viability Furthermore security about this novel strategy.

Previously, conclusion, the rate of repeat for urethral stricture then afterward visual inside urethrotomy (VIU) will be secondary. In the exhibit study, mitomycin c might have been found to make profoundly viable On keeping those repeat from claiming urethral stricture after VIU.

\section{Conclusion}

Multiple intralesional MMC injections following VIU have a potential to markedly reduce the recurrence of urethral stricture.

\section{References}

[1] G.H. Jordan, S.M. Schlossberg, Surgery of penis and urethra. In: Wein AJ, Kavoussi LR, Novick AC (eds) Campbell-Walsh urology;vol. 9, pp. 105575,2007.

[2] N. Lumen, P. Hoebeke, B. De Troyer, W .Oosterlinck,Aetiology of urethral stricture disease: an analysis of 268 patients. Eur Urol., Vol.8, pp.158,2009.

[3] R. Santucci, L. Eisenberg, Urethrotomy has a much lower success rate than previously reported. J Urol;vol.183, PP.1859-62,2010.

[4] O. Kurt, F. Gevher, C.M. Yazici, M. Erboga, M. Dorgu, C .Aktas, Effect of Mitomycin - $\mathrm{C}$ and Triamcinolone on preventing urethral Strictures. Int Braz J Urol, Vol.43 (5), PP.939-945, 2017.

[5] U.M. Giovannini, Treatment of scars by steroid injections. Wound Repair Regen;vol.10, PP.1167,2002.

[6] C. Su, T. Sui, X. Zhang, H. Zhang, X. Cao, Effect of topical application of mitomycin-C on wound healing in a postlaminectomy rat model: an experimental study. Eur J Pharmacol, Vol.674, PP.7-12, 2012.

[7] G.H. Jordan, S.M. Schlossberg, Surgery of the penis and urethra. In: Retik AB, Vaughan ED, Wein AJ, editors. Campbell's urology. Philadelphia: Saunders, Vol.8, PP. 3915-30, 2002.

[8] W.T. Bradner, C. Mitomycin, a clinical update. Cancer Treat Rev, Vol.27, PP.35-50, 2001.

[9] S.A. Estrem, R.N .Van Leeuwen, Use of mitomycin C for maintaining myringotomy patency. Otolaryngol Head Neck Surg, Vol.122, PP.8-10,2000.

[10] H. Fontana, K. Nouri-Mahdavi, J .Caprioli, Trabeculectomy with mitomycin $\mathrm{C}$ in pseudophakic patients with openangle glaucoma: outcomes and risk factors for failure.Am J Ophthalmol, Vol.141, PP.6529,2006. 